\title{
Incidence of inferior alveolar nerve affection with and without nerve exposure during bilateral sagittal split osteotomy
}

\section{Original Article}

Abdelfattah A. Sadakah and Mohammad A. Elshall

Department of Oral and Maxillofacial Surgery, Faculty of Dentistry, Tanta University, Tanta, Egypt

\begin{abstract}
Objective: The aim of this study was to determine the presence and severity of inferior alveolar nerve (IAN) affection during bilateral sagittal split osteotomy (BSSO) in two groups of patients with and without direct exposure and visualization of the nerve during surgical procedure.

Patients and Methods: In this prospective randomized clinical study, 14 patients (28 sides) indicated for BSSO were included. The sides were randomly divided into two groups with equal number of sides (14 sides). Group I with wide soft tissue dissection of the medial side of the ramus and exposure of IAN above the ligula and group II with minimal soft tissue dissection of the medial side of the ramus without exposure of IAN. For evaluation of neurosensory function of IAN, two methods were used including subjective evaluation and two-point discrimination test.

Results: According to the subjective evaluation, there was a statistically significant difference between both groups in favor of group II in all follow-up recalls except in the final one at 12 months postoperatively. Considering the results of two-point discrimination test, the improvement obviously continued during the successive follow-up periods in both groups, with a statistically significant difference in favor of group II until the ninth month, and then in the last follow-up at the $12^{\frac{\text { th}}{\mathrm{m}}}$ month, the records were almost equal.

Conclusion: To markedly reduce the postoperative neurosensory disturbances of IAV and to accelerate the full recovery of sensation of the lower lip and chin regions following BSSO, limited exposure and dissection of the medial soft tissues of the ramus should be practiced with avoidance of direct exposure and manipulation of IAN.
\end{abstract}

Received: 20 ${ }^{\text {th }}$ December, 2017, Accepted: 20는 January, 2018.

Key Words: inferior alveolar nerve neurosensory disturbance, sagittal split ramus osteotomy, surgical technique.

Corresponding Author: Mohammad A. Elshall, BDS, MSc, PhD, Department of Oral and Maxillofacial Surgery, Faculty of Dentistry, Tanta University, Tanta 31527, Egypt; Tel.: + 20127331 4717; fax: +20 403344 173;

E-mail: drelshall@yahoo.com

ISSN: 2090-097X, January, Vol. 9, No. 1.

\section{INTRODUCTION}

The bilateral sagittal split osteotomy (BSSO) is considered the most commonly used surgical procedure for treating mandibular deformity. The osteotomy in BSSO is performed in close proximity to the inferior alveolar nerve (IAN), and thus IAN damage often results [1].

Neurosensory disturbances (NSD) of IAN after mandibular osteotomies vary from 0 to $100 \%$. Deficits include numbness or unusual sensations in the lower lip, chin, teeth, and gingiva. Paresthesia is usually transient but may be permanent [2].

IAN damage accounts for most postoperative complications of BSSO. IAN injury during surgery largely results from manipulation of the nerve or surrounding structures or from direct injury to the nerve during the operation. IAN damage can consist of complete or partial transection, extension, compression, crushing, or ischemia [3-5].

There is wide variation in the reporting of the incidence of IAN disturbances after orthognathic surgery. The incidence of nerve damage apparent at operation during BSSO has been reported to vary from 1.3 to $18 \%$, whereas postoperative sensory disturbances in the lower lip and chin have been reported to occur in $9-85 \%$ of operated sides [6]. These variations have been attributed to several factors, such as variability in nerve function assessments, variation in follow-up periods between studies, and assessor experience [1].

Many tests are used to evaluate the sensory integration and the severity of sensory disturbance of the lower lip including: temperature sensitivity, two-point discrimination 
(TPD) threshold, light touch perception, and trigeminal somatosensory-evoked potentials $[7,8]$.

Sagittal split ramus osteotomy (SSRO) may damage the IAN and cause NSD in the lower lip, which is one of the most common and unpleasant postoperative complications. The NSD caused by damage to the IAN is reportedly 9-84.6\%. Even with careful surgery, injury to the IAN appears unpredictable [9].

Multiple factors are considered responsible for the development of NSD after SSRO, including fixation methods, patient age, surgical procedures, improper splinting, magnitude of mandibular movement, experience of surgeons, and timing of the postoperative neurosensory evaluation. Although many investigators have reported NSD after SSRO, the precise factors remain to be elucidated $[6,10]$.

Other important factors known to cause postoperative NSD include the surgical procedure of the medial periosteal dissection and compression of the nerve on the medial side of the mandibular ramus by the protecting retractors. The surgical area and the space situated in the medial aspect of the mandibular ramus is important in SSRO; it is prepared for subperiosteal dissection to insert a suitable retractor such as channel retractor just superior to the lingula to protect IAN and cut the mandible at the horizontal line. During this surgical manipulation, the IAN is likely to be stretched excessively by the channel retractor to allow better visualization in this narrow surgical field. This relationship between the surgical space located medial to the mandibular ramus and the development of NSD remains to be evaluated [11].

Based on the previous reported literature debate regarding the NSD of IAN after BSSO, this prospective clinical study was conducted to investigate the relationship between the surgical manipulation of soft tissues medial to the ramus with and without exposure of IAV and the postoperative occurrence of NSD, aiming to reach to a proper surgical technique that greatly reduces the occurrence of this reported common complication.

\section{PATIENTS AND METHODS}

In this prospective randomized clinical study, 14 patients (28 sides) indicated for BSSO with or without concomitant maxillary surgery were included. There were nine female and five male patients, with a mean age of 22.5 years and a range of 18-30 years.

The surgical treatment was either mandibular advancement (six patients) or setback (eight patients). The 28 sides were randomly divided into two groups: group I (right side) comprises 14 right sides of the patients in whom wide soft tissue dissection of the medial side of the ramus was performed with exposure of IAN above the ligula, and group II (left side) comprises 14 left sides of the patients in whom minimal soft tissue dissection of the medial side of the ramus without exposure of IAN was performed.

All the patients included in this study were adult patients (18 years or older), with normal sensation of the lower lip, and they had the usual preoperative and postoperative orthodontics with fixed appliances.

Exclusion criteria included patients in need for other concomitant mandibular osteotomies such as genioplasty procedures and patients with obvious injury of IAN during the surgical procedure.

The lower lip and chin sensation was examined bilaterally for all patients immediately preoperative and 1 week, 2 weeks, 1 month, 3 months, 6 months, 9 months, and 12 months postoperatively. The tests of NSD were done by an independent investigator (blind evaluation). Ethical approval was obtained from the Research Ethics Committee of Faculty of Dentistry, Tanta University, Egypt.

\section{Evaluation of neurosensory function of inferior alveolar nerve}

Subjective evaluation was done through asking the patient about any area of hypoesthesia, numbness, tingling, or pain. The time required to recover full and normal sensibility of the lip and chin was recorded during the follow-up period. According to Panula et al. [12], the subjective sensation (without discriminating between the lip and the chin) on both sides was inquired. A threepoint scale was used: (a) normal, (b) slightly altered, not disturbing, and (c) severely disturbing.

Objective evaluation was done using a TPD test. It was performed with the patient's eyes closed by placing a closed caliper on a specific skin region and then it was opened progressively in $2 \mathrm{~mm}$ increments while one end of it remains stable until the patient was able to distinguish between the two points.

The normal measures for this test vary from 2 to 9 $\mathrm{mm}$. The readings are considered as moderately reduced sensation between 10 and $15 \mathrm{~mm}$, severely reduced between 16 and $20 \mathrm{~mm}$ and considered absent above $20 \mathrm{~mm}$ [13].

\section{Surgical technique}

All patients were operated under general anesthesia with nasotracheal intubation. The general surgical steps of performing BSSO were based on the original principles described by Dal Pont [14] after modification of Obwegeser technique. The soft tissue incision started at mid-point from the anterior ramus and extended along the external oblique ridge buccally to the first molar about $4 \mathrm{~cm}$; the medial soft tissues of the ascending ramus were accessed 
subperiosteally, and the lingula over the mandibular foramen was identified.

In group I (right side), a wide exposure of the medial ramus was utilized for clear visualization of the foramen and the IAN while entering the foramen. A wide retractor was used to protect the nerve and widely expose the area while being supported on the posterior border of the medial side of the ramus (Fig. 1).

(a)

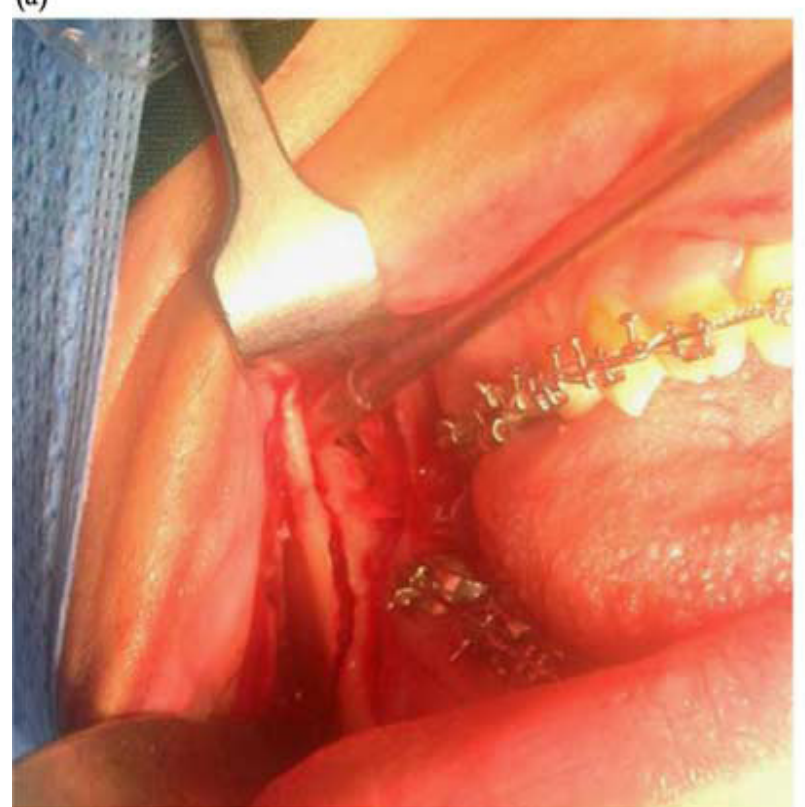

In group II (left side), a different surgical exposure technique was used in which a limited subperiosteal dissection was performed above the lingula creating a tunnel not reaching the full depth of the medial side of the ramus. A small retractor or a wide rounded periosteal elevator was used to protect the medial soft tissues while supported on the posterior third of the medial ramus. The nerve was not exposed or visualized while entering the foramen (Fig. 2).

(b)

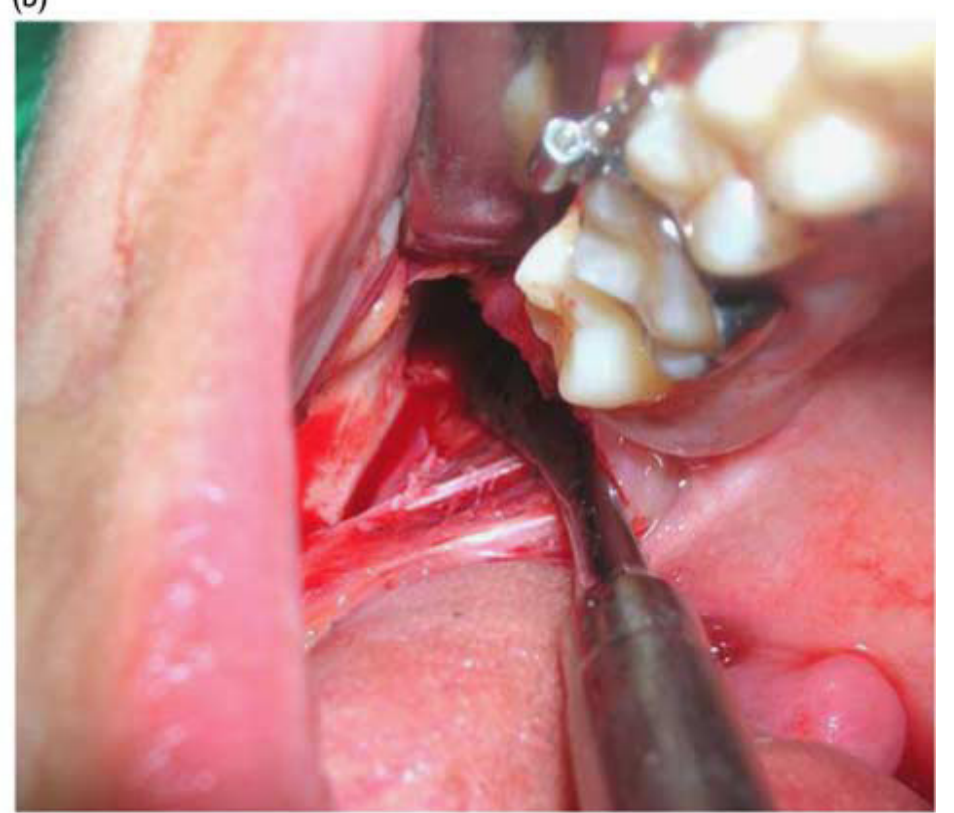

Fig. 1: ( $a$ and b) Wide surgical exposure of the medial side of the ramus performed in group I (right sides).

(a)

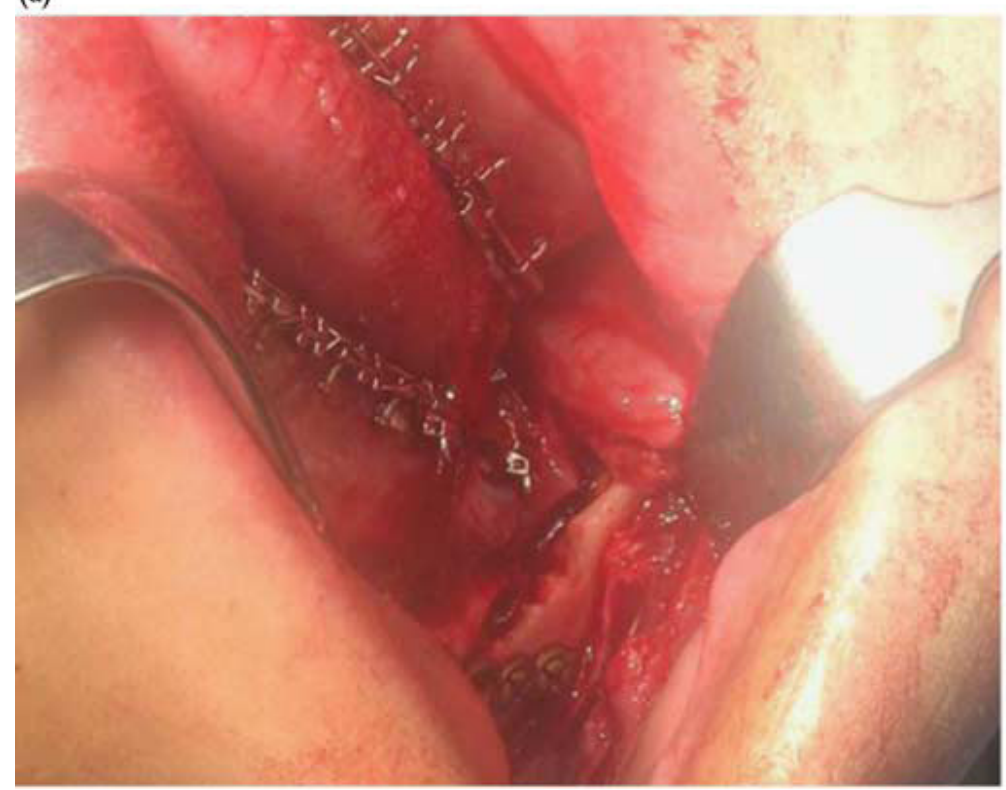

(b)

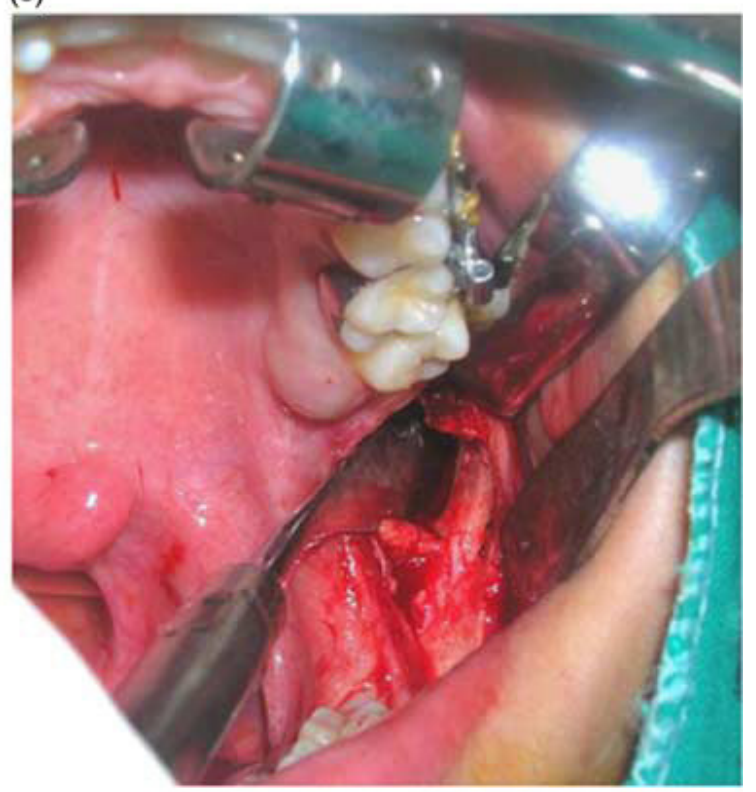

Fig. 2: (a and b) Limited surgical exposure of the medial side of the ramus performed in group II (left sides). 
The osteotomy cuts were done using a long Lindemann burr starting by the horizontal cuts at the medial side of the ramus, and then the anterior vertical buccal osteotomy extending from the lower border of mandible mesial to the second molar to the external oblique ridge was done, followed by connecting the two osteotomy cuts through the anterior border of the ramus and retromolar area.

It was then followed by splitting and separation of the proximal and distal fragments with thin chisels with great care to avoid nerve injury. During the separation, the osteotomy site was carefully observed to identify the IAN, and when it was present in the proximal segment, a gentle release with a blunt-ended instrument was done.

Any sharp or irregular bony margin were smoothed up to facilitate bony approximation and adaptation and to prevent any potential for nerve injury. Copious saline irrigation was used to wash out any residual bony fragments. Internal fixation was applied using miniplates and monocortical screws at the upper part of buccal osteotomy in all patients. No immediate postoperative intermaxillary elastics were used.

All patients were followed up for 1 year starting 1 week postoperatively and then 2 weeks, 1 month, 3 months, 6 months, 9 months, and 12 months. All data were recorded and statistically analyzed using the statistical package for the social sciences (SPSS version 18.0; SPSS Inc., Chicago, USA). Comparison between the results of the two groups was performed using Student's t-test, and probabilities of 0.05 or less were accepted as significant.

\section{RESULTS}

The main concern of the patients seeking treatment was facial esthetics followed by improper eating and bad oral hygiene.

There were two encountered intraoperative complications in this study that occurred in two different patients who were excluded from the study and replaced by another uncomplicated two cases. In one of them, a fracture of the buccal side of the proximal segment occurred during split, and the other one had inadvertent cutting of left IAN during splitting of the segments at the buccal side and the trial of retrieving the nerve from the proximal segment.

There were no reported major complications in the operated sides of all patients enrolled in this study such as fracture of the osteotomized segments or abnormal bleeding during surgery. Postoperatively, no patient had wound dehiscence, infection, nonunion, bone instability, or long-term malocclusion. During medial soft tissue dissection and retraction, evident injuries at the lingula area or of the IAN were not observed in any of the patients. The remaining parts of the surgical procedure were uneventful and straightforward according to the planned osteotomies and segment repositioning and fixation.

The surgical procedure was generally easier and faster in group II cases (limited exposure) than in group I during medial soft tissue dissection and horizontal osteotomy through the ramus. It needs only some practice in accurate detection and confirmation of lingula position and localization of osteotomy line that is acquired by the successive operations.

Regarding the subjective evaluation of the NSD/ neurosensory deficits of IAN that only manifested and described by patients, the results showed that in group I (wide surgical exposure) $28.5 \%$ of patients had normal sensation of the lower lip and chin region during the postoperative 2 weeks, whereas in group II (limited surgical exposure), this percentage was higher reaching 42.9 and $50 \%$ in the first and second weeks, respectively, giving a statistically significant difference. The patients complaining of a severely disturbing sensation were comparable in both groups during that period.

One month postoperatively, the sensation obviously improved and showed that $42.9 \%$ had normal sensation (sore 1 ); $42.9 \%$ had slightly altered but not disturbing sensation (score 2), and only $14.2 \%$ (two patients) had severely disturbing sensation (score 3) in group I patients. The sensation greatly improved in group II patients as well with statistically significant difference in favor of this group, which showed that $64.3 \%$ had score $1,57.1 \%$ had score 2 , and only $7.1 \%$ (one patient) had score 3 .

The sensation slightly improved at 3 months postoperatively in both groups but with a statistically significant difference in favor of group II, which had no patients with score 3 . The improvement continued gradually at the 6-month period in both groups with the same statistical difference but without any patient with score 3. Most of the patients in group II gained full recovery of normal sensation.

At the 9-month period, all patients in group II entirely recovered with normal sensation (score 1), whereas in group I, 28.5\% (four patients) were still complaining of altered sensation (score 2). At 12 months, all but one patient in group I completely recovered with normal sensation (score 1). The results of this subjective test are illustrated in Table 1.

Therefore, according to this subjective evaluation, there was a statistically significant difference between both groups in favor of group II in all follow-up recalls except in the final one at 12 months postoperatively. 
Table 1: Number of sides and percentage with postoperative subjective symptoms of neurosensory disturbances of inferior alveolar nerve of both groups during the follow-up period.

\begin{tabular}{|c|c|c|c|c|c|c|c|}
\hline \multirow[b]{2}{*}{ Follow-up period } & \multicolumn{3}{|c|}{ Group I (right side): wide exposure } & \multicolumn{3}{|c|}{ Group II (left side): limited exposure } & \multirow{2}{*}{$\begin{array}{l}\text { Significance of recorded } \\
\text { score } 1 \text { : normal } \\
\text { sensation }(P \leq 0.05)^{*} \\
\text { t-Test }\end{array}$} \\
\hline & Score 1 & Score 2 & Score 3 & Score 1 & Score 2 & Score 3 & \\
\hline 1 week & $4(28.5)$ & $6(42.9)$ & $4(28.5)$ & $6(42.9)$ & $4(28.5)$ & $4(28.5)$ & $\leq 0.05^{*}$ \\
\hline 2 weeks & $4(28.5)$ & $7(50.0)$ & $3(21.5)$ & $7(50.0)$ & $5(35.8)$ & $2(14.2)$ & $\leq 0.05^{*}$ \\
\hline 1 month & $6(42.9)$ & $6(42.9)$ & $2(14.2)$ & $9(64.3)$ & $4(57.1)$ & $1(7.1)$ & $\leq 0.05 *$ \\
\hline 3 months & $7(50.0)$ & $6(42.9)$ & $1(7.1)$ & $10(71.5)$ & $4(28.5)$ & 0 & $\leq 0.05^{*}$ \\
\hline 6 months & $8(57.1)$ & $6(42.9)$ & 0 & $12(85.8)$ & $2(14.2)$ & 0 & $\leq 0.05^{*}$ \\
\hline 9 months & $10(71.5)$ & $4(28.5)$ & 0 & $14(100)$ & 0 & 0 & $\leq 0.05^{*}$ \\
\hline 12 months & $13(92.9)$ & $1(7.1)$ & 0 & $14(100)$ & 0 & 0 & $>0.05$ \\
\hline
\end{tabular}

Score 1: normal; score 2: slightly altered, not disturbing; score 3: severely disturbing.

*Significant.

Considering the objective results of NSD of IAN using the TPD test, the preoperative measurement values for all patients enrolled in this study ranged from 2 to $9 \mathrm{~mm}$ with a mean of $6 \mathrm{~mm}$.

The postoperative results showed that in group I (wide surgical exposure) only $21.5 \%$ of patients can discriminate two-point sensation in $5-9 \mathrm{~mm}$ distance (normal sensation), 21.5\% between 10 and $15 \mathrm{~mm}$ (moderately reduced sensation), $42.9 \%$ between 16 and $20 \mathrm{~mm}$ (severely reduced), and $14.2 \%$ above $20 \mathrm{~mm}$ (absent sensation) during the first week, whereas in group II (limited surgical exposure), close but better results were recorded with only one $(7.1 \%)$ patient able to discriminate above $20 \mathrm{~mm}$. No patients in both groups can discriminate smaller distances between 2 and $4 \mathrm{~mm}$ in this period which reflects the immediate postsurgical affection of the neurosensory function of IAN because of surgical trauma and soft tissue edema of IAN and surrounding tissues.

During the second week, the condition remains somewhat stable in both groups regarding the normal sensation record between 5 and $9 \mathrm{~mm}$ and no one can discriminate $2-4 \mathrm{~mm}$ distance. There is a considerable increase in number of patients who can discriminate between 10 and $15 \mathrm{~mm}$ in group I from three $(21.5 \%)$ to seven $(50.0 \%)$ patients. No patients in both groups had absent sensation as no records were above $20 \mathrm{~mm}$ distance.

One month postoperatively, still no patient can detect smaller distances between 2 and $4 \mathrm{~mm}$ in both groups, but there was obvious improvement in overall discrimination with statistically significant difference in favor of group II. In group I, 42.9\% were between 10 and $15 \mathrm{~mm}$ and $21.5 \%$ between 16 and $20 \mathrm{~mm}$, whereas in group II, $35.8 \%$ were between 10 and $15 \mathrm{~mm}$ and only $7.1 \%$ (one patient) between 16 and $20 \mathrm{~mm}$. No one from both groups was found to be above $20 \mathrm{~mm}$ distance.

During the 3-month recording period, there was marked improvement in both groups but with a statistically significant difference in favor of group II. Overall, $35.8 \%$ of group II and $21.5 \%$ of group I could discriminate between 2 and $4 \mathrm{~mm}$ distance, and $35.8 \%$ of both groups were between 5 and $9 \mathrm{~mm}$. No patients in group II were between 16 and 20 or above $20 \mathrm{~mm}$, whereas only one patient in group I was between 16 and $20 \mathrm{~mm}$. So most of the patients in both groups had normal sensation during that period $-10(71.6 \%)$ patients in group II and eight (57.3\%) patients in group I with a statistically significant difference in favor of group II.

The improvement obviously continued during the succeeding follow-up periods in both groups with a statistically significant difference in favor of group II until the ninth month, and then during the last follow-up at the 12th month, the records were almost equal without any statistically significant difference in both groups.

At the sixth month, $57.1 \%$ of group II and $35.8 \%$ in group I could discriminate between 2 and $4 \mathrm{~mm}$ distance, $28.5 \%$ of both groups were between 5 and $9 \mathrm{~mm}$, and $14.2 \%$ of group II and $35.8 \%$ of group I were between 10 and $15 \mathrm{~mm}$. No patients in both groups were between 16 and 20 or above $20 \mathrm{~mm}$. So an increased number of patients in both groups had normal sensation during that period: 12 (85.6\%) patients in group II and nine (64.3\%) patients in group I.

At the ninth month, there was a marked improvement in both groups with a statistically significant difference also in favor of group II Overall, $85.8 \%$ of group II and 
$57.1 \%$ in group I could discriminate between 2 and $4 \mathrm{~mm}$ distance, and $14.2 \%$ of group II and $21.5 \%$ of group I were between 5 and $9 \mathrm{~mm}$. Only $21.5 \%$ of group II patients were between 10 and $15 \mathrm{~mm}$, but no patients in group II were between 10 and 15 or above.

At the last follow-up period (12th month), there was almost stable results in group II whereas there was a marked improvement in group I patients in comparison with the previous period of recording. There was a statistically nonsignificant difference between both groups. In total, 13 (92.9\%) patients of group II and 12 $(85.8 \%)$ patients in group I could discriminate between 2 and $4 \mathrm{~mm}$ distance. Only one (7.1\%) patient in both groups was between 5 and $9 \mathrm{~mm}$. No one in group II was between 10 and $15 \mathrm{~mm}$ or above, but only one patient in group I (7.1\%) was in this recorded distance. So by the end of the follow-up period at the 12th month, all patients in group I attained normal sensation of the skin of the lip and chin region with full recovery of the neurosensory function of the IAN. Almost all patients of group I got the same results of improvement with complete recovery, as 13 patients were within the records of normal sensation values and only one $(7.1 \%)$ was within the value of moderately reduced sensation. The results of this objective TPD test are shown in Table 2.

Finally, no statistically different significance was found between the two methods used in this study for evaluation of the NSD of IAN and in detecting the

Table 2: Number of sides and percentage of postoperative values of two-point discrimination test for both groups during the followup period

\begin{tabular}{|c|c|c|c|c|c|c|c|c|c|c|c|c|c|c|}
\hline \multirow[b]{2}{*}{$\begin{array}{l}2 \mathrm{PD} \\
\text { value } \\
(\mathrm{mm})\end{array}$} & \multicolumn{2}{|c|}{1 week } & \multicolumn{2}{|c|}{2 wweeks } & \multicolumn{2}{|c|}{1 month } & \multicolumn{2}{|c|}{3 months } & \multicolumn{2}{|c|}{6 months } & \multicolumn{2}{|c|}{9 months } & \multicolumn{2}{|c|}{12 months } \\
\hline & $\begin{array}{c}\text { Group } \\
\text { I }\end{array}$ & $\begin{array}{c}\text { Group } \\
\text { II }\end{array}$ & $\begin{array}{c}\text { Group } \\
\text { I }\end{array}$ & $\begin{array}{c}\text { Group } \\
\text { II }\end{array}$ & $\begin{array}{c}\text { Group } \\
\text { I }\end{array}$ & $\begin{array}{l}\text { Group } \\
\text { II }\end{array}$ & $\begin{array}{c}\text { Group } \\
\text { I }\end{array}$ & $\begin{array}{c}\text { Group } \\
\text { II }\end{array}$ & $\begin{array}{c}\text { Group } \\
\text { I }\end{array}$ & $\begin{array}{c}\text { Group } \\
\text { II }\end{array}$ & $\begin{array}{c}\text { Group } \\
\text { I }\end{array}$ & $\begin{array}{c}\text { Group } \\
\text { II }\end{array}$ & $\begin{array}{c}\text { Group } \\
\text { I }\end{array}$ & $\begin{array}{c}\text { Group } \\
\text { II }\end{array}$ \\
\hline \multirow[t]{2}{*}{$2-4$} & & & & & & & $\begin{array}{c}3 \\
(21.5)\end{array}$ & $\begin{array}{c}5 \\
(35.8)\end{array}$ & $\begin{array}{c}5 \\
(35.8)\end{array}$ & $\begin{array}{c}8 \\
(57.1)\end{array}$ & $\begin{array}{c}8 \\
(57.1)\end{array}$ & $\begin{array}{c}12 \\
(85.8)\end{array}$ & $\begin{array}{c}12 \\
(85.8)\end{array}$ & $\begin{array}{c}13 \\
(92.9)\end{array}$ \\
\hline & & & & & & & $\begin{array}{c}\leq \\
0.05^{*}\end{array}$ & $\begin{array}{c}\leq \\
0.05^{*}\end{array}$ & $\begin{array}{c}\leq \\
0.05^{*}\end{array}$ & $>0.05$ & & & & \\
\hline \multirow[t]{2}{*}{$5-9$} & $\begin{array}{c}3 \\
(21.5)\end{array}$ & $\begin{array}{c}5 \\
(35.8)\end{array}$ & $\begin{array}{c}3 \\
(21.5)\end{array}$ & $\begin{array}{c}6 \\
(42.9)\end{array}$ & $\begin{array}{c}5 \\
(35.8)\end{array}$ & $\begin{array}{c}8 \\
(57.1)\end{array}$ & $\begin{array}{c}5 \\
(35.8)\end{array}$ & $\begin{array}{c}5 \\
(35.8)\end{array}$ & $\begin{array}{c}4 \\
(28.5)\end{array}$ & $\begin{array}{c}4 \\
(28.5)\end{array}$ & $\begin{array}{c}3 \\
(21.5)\end{array}$ & $\begin{array}{c}2 \\
(14.2)\end{array}$ & $1(7.1)$ & $1(7.1)$ \\
\hline & $\underset{0.05^{*}}{\leq}$ & $\underset{0.05^{*}}{\leq}$ & $\underset{0.05^{*}}{\leq}$ & & & & & $>0.05$ & & & & & & \\
\hline $10-15$ & $\begin{array}{c}3 \\
(21.5)\end{array}$ & $\begin{array}{c}5 \\
(35.8)\end{array}$ & $\begin{array}{c}7 \\
(50.0)\end{array}$ & $\begin{array}{c}6 \\
(42.9)\end{array}$ & $\begin{array}{c}6 \\
(42.9)\end{array}$ & $\begin{array}{c}5 \\
(35.8)\end{array}$ & $\begin{array}{l}5 \\
(35.8)\end{array}$ & $\begin{array}{l}4 \\
(28.5)\end{array}$ & $\begin{array}{c}5 \\
(35.8)\end{array}$ & $\begin{array}{c}2 \\
(14.2)\end{array}$ & $\begin{array}{c}3 \\
(21.5)\end{array}$ & 0 & $1(7.1)$ & 0 \\
\hline $16-20$ & $\begin{array}{c}6 \\
(42.9)\end{array}$ & $\begin{array}{c}3 \\
(21.5)\end{array}$ & $\begin{array}{c}4 \\
(28.5)\end{array}$ & $\begin{array}{c}2 \\
(14.2)\end{array}$ & $\begin{array}{c}3 \\
(21.5)\end{array}$ & $1(7.1)$ & $1(7.1)$ & 0 & 0 & 0 & 0 & 0 & 0 & 0 \\
\hline$>20$ & $\begin{array}{c}2 \\
(14.2)\end{array}$ & $1(7.1)$ & 0 & 0 & 0 & 0 & 0 & 0 & 0 & 0 & 0 & 0 & 0 & 0 \\
\hline
\end{tabular}

2PD, two-point discrimination.

*Significant.

Table 3: Comparison between the two methods used to evaluate neurosensory disturbances of inferior alveolar nerve of both groups regarding number of patients and percentage with normal sensation during the follow-up period.

\begin{tabular}{|c|c|c|c|c|c|c|}
\hline \multirow[b]{2}{*}{ Follow-up period } & \multicolumn{2}{|c|}{$\begin{array}{l}\text { Group I (right side): } \\
\text { wide exposure }\end{array}$} & \multirow{2}{*}{$\begin{array}{c}\mathrm{t} \text {-Test } \\
\mathrm{P} \leq 0.05^{*}\end{array}$} & \multicolumn{2}{|c|}{$\begin{array}{l}\text { Group II (left side): } \\
\text { limited exposure }\end{array}$} & \multirow{2}{*}{$\begin{array}{c}\mathrm{t}-\text { Test } \\
\mathrm{P} \leq 0.05^{*}\end{array}$} \\
\hline & $\begin{array}{l}\text { Subjective } \\
\text { evaluation }\end{array}$ & 2PD test & & $\begin{array}{l}\text { Subjective } \\
\text { evaluation }\end{array}$ & 2PD test & \\
\hline 1 week & $4(28.5)$ & $3(21.5)$ & $>0.05$ & $6(42.9)$ & $5(35.8)$ & $>0.05$ \\
\hline 2 weeks & $4(28.5)$ & $3(21.5)$ & $>0.05$ & $7(50.0)$ & $6(42.9)$ & $>0.05$ \\
\hline 1 month & $6(42.9)$ & $5(35.8)$ & $>0.05$ & $9(64.3)$ & $8(57.1)$ & $>0.05$ \\
\hline 3 months & $7(50.0)$ & $8(57.3)$ & $>0.05$ & $10(71.5)$ & $10(71.5)$ & \\
\hline 6 months & $8(57.1)$ & $9(64.3)$ & $>0.05$ & $12(85.8)$ & $12(85.8)$ & \\
\hline 9 months & $10(71.5)$ & $11(78.6)$ & $>0.05$ & $14(100)$ & $14(100)$ & \\
\hline 12 months & $13(92.9)$ & $13(92.9)$ & & $14(100)$ & $14(100)$ & \\
\hline
\end{tabular}

2PD, two-point discrimination.

*Significant. 
number of patients with postoperative normal sensation when comparing the results of both groups during the follow-up periods as illustrated in Table 3.

\section{DISCUSSION}

Some oral and maxillofacial surgeons believe that wide exposure and direct visualization of the IAN during medial dissection of the ramus is the ideal and better way for the nerve protection and prevention of its injury. However, others have the opposite concept in that minimal dissection and avoidance of nerve exposure have the maximum effect on nerve protection. Therefore, this study was planned to investigate this critical surgical point during BSSO aiming to reduce the postoperative occurrence of lip and chin paresthesia with its negative effect on patients'quality of life owing to distress and discomfort, and to accelerate the time of full sensation recovery, or at least to prevent permanent nerve damage.

Two patients were initially included in this study and then excluded owing to occurrence of surgical complications and replaced by another two patients. In one of them, an inadvertent cutting of left IAN occurred, and it was managed by direct macroscopic suturing in four crossed points with 60 / vicryl sutures. This patient gradually improved postoperatively regarding lower lip sensation until he gained complete recovery of the nerve function 15 months later. The other one had a fracture of the buccal side of the proximal segment, which occurred during split and was managed by anatomic reduction and fixation with four-hole miniplate and monocortical screws.

The results of this study showed that the limited surgical exposure and limited soft tissue manipulation at the medial side of the ramus during horizontal osteotomy (group II, left sides) produced better results than the wide surgical exposure and visualization of IAN for protection (group I, right sides). This is evidenced by the statistically significant difference between both groups regarding the occurrence of postoperative NSD during the follow-up periods until the ninth month.

This finding is supported by some previously reported studies which showed that the occurrence of postoperative NSD of the IAN after SSRO is actually not limited to only one variable, but certainly one of the major and frequent reported causes is surgical manipulation during medial dissection of soft tissues related to the lingula $[2,11,12,15]$. On the contrary, a study carried out by Teerijoki-Oksa et al. [16] to detect the risk factors of nerve injury during mandibular sagittal split osteotomy concluded that exposure or manipulation of the IAN usually had no effect on nerve function, but the IAN conduction tended to be more disturbed in cases with nerve laceration.

In another study in agreement with the previous one, Ylikontiola et al. [17] mentioned that the medial tissue retraction had no obvious influences on the IAN function, and they argued that the difference compared with their study and many other studies is that they did not actually measure the sensibility but interviewed the patients for their subjective sensation.

However, also in agreement with the results of the present study, it was reported that the known causal factors of postoperative trigeminal nerve hypoesthesia include medial periosteal dissection, exposure of the alveolar nerve during the split, compression injury at the time of fixation, and postoperative swelling $[18,19]$.

Mommaerts [20] demonstrated a low incidence of NSD development 1 week after surgery (27.4\%) by using an endoscopically assisted SSRO procedure with reduced periosteal degloving. He found that this method is a useful way to increase control over the osteotomy because of the good visibility provided by illumination and magnification. He concluded that limiting periosteal degloving will reduce excessive stretching of the nerve, and that may aid in the prevention of NSD.

Moreover in accordance with the results of this study, it was stated that although the surgical technique of SSRO may cause direct damage to the IAN by way of the saw or osteotome used during bone splitting, manipulation of the IAN on the medial side of the mandibular ramus has also been considered as a possible causal factor of NSD [6].

In modification of their opinion, Teerijoki-Oksa et al. [2] used a purely objective assessment by intraoperative electrophysiological monitoring and demonstrated that IAN function was considerably disturbed during medial soft tissue dissection around the lingula. Especially when there is a tunnel-visional space, such as that at the medial surface of the ramus, surgeons are more prone to stretch the IAN bundle to obtain a wider surgical view.

Kuroyanagi and Shimozato [11], in a study for prediction of neurosensory alterations after SSRO, reported that the development of NSD is related to the surgical space on the medial side of the mandibular ramus and subsequent manipulation of the IAN in that region. Limited periosteal degloving prevents excessive stretching of the IAN during SSRO, thus lowering NSD incidence. 
In the same context, Panula et al. [12], found that gentle dissection of soft tissue medial to the ascending ramus of the mandible is an important factor in the efforts to prevent dysfunction of the IAN in BSSO. Higher age is an evident risk factor, and subjective sensation correlates with TPD in the lower lip.

Panula et al. also reported a point of weakness in their study in using two different bone-cutting instruments (saw in one side and burr in the opposite side). They found that saw may need more retraction than a burr and therefore cause more traction on the soft tissues, including the nerve; it may also cause a different type of damage compared with a rotating instrument. This could be thought theoretically to cause instrumentdependent difference in the results. So, they recommend the use of burr in performing the horizontal osteotomy, because it does not need as much space as saw blade. They stated that if saw blade is used, it can be tilted to a 45-508 angle against bone, to avoid too much tension to soft tissues in the medial side.

In this study and in compliance with that previously recommended, a long Lindemann burr was used during the osteotomies of all sites including the critical area under research of the medial side of the ramus. It was found to be efficient, easy, and adequate enough to perform the osteotomy with the limited subperiosteal dissection and finally enabling fine splitting.

The affection of IAN is manifested clinically by paresthesia (altered sensation; hypoesthesia, numbness, and tingling) in the region of the lower lip and chin. This type of sensation is described by patients and is completely subjective and varies from one to another and from time to time.

To get a standardized and uniform data, some methods of objective detection were used including the TPD that was documented to be an effective measure of NSD in many previous studies that reported that the evaluation method to be used should be reproducible, easy to be performed, and simple chair-side technique $[12,21]$.

Many methods were used to evaluate IAN affection through altered sensation or hypoesthesia in the supplied skin areas (lower lip and chin) varying between subjective and objective methods. Those tests $(>15)$ were mainly subjective, being the most commonly used is the TPD test in mandibular osteotomies studies (62\%) [21].

The 2 methods used in this study (combining subjective and objective data) for evaluation of NSD of IAN were found to be effective, simple, and easy to be performed during the clinical follow-up settings.
As a result of this study, those 2 methods are proved to be correlated to each other and showed close and comparable results without statistically significant difference. These findings are supported by many earlier studies $[6,12,22]$.

However, Agbaje et al. [1], in a systematic review of the incidence of IAN injury in BSSO and the assessment of NSD, stated that they observed the incidence of IAN impairment was higher in reports employing subjective methods than when objective methods were used.

According to Colella et al. [23], the higher frequency of IAN impairment indicated by subjective methods suggests that subjective reporting may include sensory impairments that do not appear to be confirmed by objective testing. It has been argued that patient satisfaction does not depend on objective test results but rather on patient perceptions of altered sensation following orthognathic surgery [24].

In a study by Westermark et al. [6], more sophisticated methods, such as light touch thresholds using monofilaments and thermal thresholds, were compared with subjective sensitivity scores. They found a positive correlation between subjective evaluation and objective assessment of the sensitivity of the lower lip.

In fact, the TPD method used in this study should be considered a partial objective method or in other words objective/subjective because it still depends on the patient reaction and interpretation. However, a previous study carried out by Nesari et al. [15] in 2005 used a purely subjective method of a two-degree scale - normal sensitivity or any sensory reduction - during evaluation of 68 patients (at 136 operated sites) after BSSO for the neurosensory recovery at 2, 6, 18, and finally 30 months. This method was based on only a questionnaire and a sharp-blunt discrimination, which was done by touching the skin with cotton swabs and with sharp and blunt ends of a probe. This procedure obviously requires the cooperation of the patient. They stated that they believe the method of choice for evaluation in their study was satisfactory.

The young age group of patients included in this study with a range of 18-30 years and a mean of 22.5 reflects the social factors in our community that motivate this age group of patients to seek improvement of their facial appearance in that time period around the common age of marriage. This is also explains the increased numbers of females over males requiring better facial esthetics.

The improvement of postoperative neurosensory function of IAN after BSSO and early recovery of its 
function was found also to be related to patient's age during the surgical operation. It was reported that early recovery is associated with younger age group as the healing potential and regeneration of tissues is still high and the physiological compensation mechanisms are highly functioning $[12,15]$.

This study investigated the NSD of IAN in multiple successive follow-up intervals of 7 appointments of clinical settings ( 1 week, 2 weeks, 1 month, 3 months, 6 months, 9 months, and 12 months) that was not reported in most of the previous studies, which give more accurate and close supervision and monitoring of the neurosensory alteration through frequent clinical evaluations.

In the current study, the NSD of the IAN was found in most of the patients within the 2 weeks postoperatively with varying degrees of intensity, but generally was the highest score that gradually decreased during the successive follow-up recalls. This is logically accepted in that period of initial healing and recovery from the surgical trauma and manipulation and its consequences of localized hematoma formation and tissue edema and inflammation.

It was recorded to be $\sim 75 \%$ in GP I and $60 \%$ in GP II in the first week, $75 \%$ in GP I and $47 \%$ in GP II in the second week, $60 \%$ in GP I and $40 \%$ in GP II in the first month, $45 \%$ in GP I and $30 \%$ in GP II in the third month, $40 \%$ in GP I and $15 \%$ in GP II in the sixth month, $25 \%$ in GP I and $0.0 \%$ completely absent) in GP II in the ninth month, and 7\% in GP I and $0.0 \%$ in GP II in the 12 th month at the last followup period. Comparable results were recorded in many other studies $[11,12,15,25]$.

Kuroyanagi et al. [11], in a study group that comprised 50 patients ( 32 women and 18 men; aged 17-44 years) who underwent consecutive series SSRO (100 SSROs in total) for the correction of mandibular prognathism, found that hypoesthesia of the lower lip at 1 week and 6 months after SSRO was observed in $33.0 \%(33100 /)$ and $11.0 \%(11100 /)$ of cases, respectively. However, NSD in the lower lip at 1 year after SSRO was detected for $2(2 \%)$ surgical sites. They also recorded significant differences between patients with NSD and without NSD at 1 week and 6 months after SSRO for the surgical space on the medial side of the mandibular ramus.

Panula et al. [12] reported that most patients had restored some sensation by the 3-month control visit, after which slower improvement toward the preoperative level continued. Five sides in both groups (33\%; 10 patients, and three patients with both sides) continued to have slightly, but not disturbingly, altered sensation at 1 year. None reported severe disturbance (grade III) at this phase.

Nesari et al. [15], in a study comprised 136 operated sites. Two months postoperatively, 52 (38\%) sites were found to have normal sensitivity and 84 sites reduced sensitivity (62\%). The incidence of disorder decreased to $52(38 \%)$ sites at 6 months, $43(32 \%)$ sites at 1.5 years, and $32(24 \%)$ sites at the final 2.5-year checkup.

Takazakura et al. [25], in investigating 20 sides with SSRO, reported that $40 \%$ recovered within 1 week or did not show any hypoesthesia. Overall, 65\% showed hypoesthesia at 3 months postoperatively. There was no permanent hypoesthesia on any side. Hypoesthesia lasted the longest on one side and continued to be followed up and recovered at 1.5 years postoperatively.

It was stated that, in general, most cases of hypoesthesia of the lower lip are temporary, but incidences of permanent hypoesthesia still occur, reportedly with a frequency of $1-48 \%$. In that previous study, the NSD remained 6 months postoperatively but had almost recovered in 1 year [11]. The severity of IAN damage by SSRO was thought to be not serious. This can be explained by the fact that compression or stretching of the nerve leads to neuropraxia or axonotmesis, which in turn leads to the impairment of sensation in the IAN [26].

However, it was explained that permanent NSD is commonly related to the anatomical bony structures not to the surgical working space. It is associated with the surgical manipulations using a saw or osteotome producing direct nerve injury $[5,27]$.

In the current study, the improvement of neurosensory function was found to be earlier and faster in GP II patients (limited surgical exposure) than in GP I patients (wide surgical exposure) as evidenced by the recorded values and subjective symptoms during the follow-up periods. The difference in improvement was always statistically significant in favor of GP II except in the last follow-up setting at the 12th month in which the difference was negligible.

\section{CONCLUSION}

To markedly reduce the postoperative NSD of IAV and to accelerate the full recovery of sensation of the lower lip and chin regions following BSSO, limited exposure and dissection of the medial soft tissues of the ramus should be practiced with avoidance of direct exposure and manipulation of IAN. 


\section{ACKNOWLEDGEMENTS}

The authors would like to thank his colleague Dr Emad Fahim, lecturer of OMS, for his valuable contribution in this paper by doing the TPD test and the statistical analysis of the tabulated results.

\section{CONFLICT OF INTEREST}

There are no conflicts of interest.

\section{REFERENCES}

1. Agbaje JO, Salem AS, Lambrichts I, Jacobs R, Politis C. Systematic review of the incidence of inferior alveolar nerve injury in bilateral sagittal split osteotomy and the assessment of neurosensory disturbances. Int J Oral Maxillofac Surg 2015; 44:447-451.

2. Teerijoki-Oksa $\mathrm{T}$, Jaaskelainen $\mathrm{S}$, Forssell $\mathrm{K}$, Virtanen A, Forssell H. An evaluation of clinical and electrophysiologic tests in nerve injury diagnosis after mandibular sagittal split osteotomy. Int J Oral Maxillofac Surg 2003; 32:15-23.

3. Wijbenga JG, Verlinden CR, Jansma J, Becking AG, Stegenga B. Longlasting neurosensory disturbance following advancement of the retrognathic mandible: distraction osteogenesis versus bilateral sagittal split osteotomy. Int J Oral Maxillofac Surg 2009; 38:719-725.

4. Yoshioka I, Tanaka T, Khanal A, Habu M, Kito S, Kodama M, et al. Relationship between inferior alveolar nerve canal position at mandibular second molar in patients with prognathism and possible occurrence of neurosensory disturbance after sagittal split ramus osteotomy. J Oral Maxillofac Surg 2010; 68:3022-3027.

5. Yamauchi K, Takahashi T, Kaneuji T, Nogami S, Yamamoto N, Miyamoto I, et al. Risk factors for neurosensory disturbance after bilateral sagittal split osteotomy based on position of mandibular canal and morphology of mandibular angle. J Oral Maxillofac Surg 2012; 70:401-406.

6. Westermark A, Bystedt $\mathrm{H}$, von Konow $\mathrm{L}$. Inferior alveolar nerve function after mandibular osteotomies. Br J Oral Maxillofac Surg 1998; $36: 425-428$.

7. de Beukelaer JG, Smeele LE, van Ginkel FC. Is short-term neurosensory testing after removal of mandibular third molars efficacious? Oral Surg
Oral Med Oral Pathol Oral Radiol Endod 1998; $85: 366-370$

8. Nakagawa K, Ueki K, Takatsuka S, Daisuke T, Yamaomoto E. Somatosensoryevoked potential to evaluate the trigeminal nerve after sagittal split osteotomy. Oral Surg Oral Med Oral Pathol Oral Radiol Endod 2001; 91:146-152.

9. Al-Bishri A, Barghash Z, Rosenquist J, Sunzel B. Neurosensory disturbance after sagittal split and intraoral vertical ramus osteotomy: as reported in questionnaires and patients' records. Int J Oral Maxillofac Surg 2005; 34:247-251.

10. Van Sickels JE, Hatch JP, Dolce C, Bays RA, Rugh JD. Effects of age, amount of advancement, and genioplasty on neurosensory disturbance after a bilateral sagittal split osteotomy. J Oral Maxillofac Surg 2002; 60:1012-1017.

11. Kuroyanagi N, Shimozato K. Prediction of neurosensory alterations after sagittal split ramus osteotomy. Int J Oral Maxillofac Surg 2013; 42:814-822.

12. Panula K, Finne K, Oikarinen K. Neurosensory deficits after bilateral sagittal split ramus osteotomy of the mandible - influence of soft tissue handling medial to the ascending ramus. Int J Oral Maxillofac Surg 2004; 33:543-548.

13. Campbell RL, Shamaskin RG, Harkins SW. Assessment of recovery from injury to inferior alveolar and mental nerves. J Oral Surg 1987; 64:519-526.

14. Dal Pont G. Retromolar osteotomy for correction of prognathism. J Oral Surg Anesth Hosp D Serv $1961 ; 19: 42-47$.

15. Nesari S, Kahnberg KE, Rasmusson L. Neurosensory function of the inferior alveolar nerve after bilateral sagittal ramus osteotomy: a retrospective study of 68 patients. Int $\mathrm{J}$ Oral Maxillofac Surg 2005; 34:495-498.

16. Teerijoki-Oksa T, Jääskeläinen SK, Forssell K, Forssell H, Vähätalo K, Tammisalo T, Virtanen A. Risk factors of nerve injury during mandibular sagittal split osteotomy. Int J Oral Maxillofac Surg 2002; 31:33-39.

17. Ylikontiola L, Kinnunen J, Oikarinen $\mathrm{K}$ Factors affecting neurosensory disturbance after 
mandibular bilateral sagittal split osteotomy. J Oral Maxillofac Surg 2000; 58:1234-1239.

18. Leira JI, Gilhuus-Moe OT. Sensory impairment following sagittal split osteotomy for correction of mandibular retrognathism. Int J Adult Orthodon Orthognath Surg 1991; 6:161-167.

19. August M, Marchena J, Donady J, Kaban L. Neurosensory deficit and functional impairment after sagittal ramus osteotomy: a long-term follow-up study. J Oral Maxillofac Surg 1998; $56: 1231-1235$

20. Mommaerts MY. Endoscopically assisted sagittal split osteotomy for mandibular lengthening: technical note and initial experience. J Craniomaxillofac Surg 2010; 38:108-112.

21. Poort LJ, van Neck JW, van der Wal KGH. Sensory testing of inferior alveolar nerve injuries: a review of methods used in prospective studies. $\mathrm{J}$ Oral Maxillofac Surg 2009; 67:292-300.

22. Blomqvist JE, Alberius P, Isaksson S. Sensibility following sagittal split osteotomy in the mandible: a prospective clinical study. Plast Reconstr Surg 1998; 102:325-341.

23. Colella G, Cannavale R, Vicidomini A, Lanza A. Neurosensory disturbance of the inferior alveolar nerve after bilateral sagittal split osteotomy: a systematic review. J Oral Maxillofac Surg 2007; 65:1707-1715.

24. Phillips C, Kim SH, Tucker M, Turvey TA. Sensory retraining: burden in daily life related to altered sensation after orthognathic surgery, a randomized clinical trial. Orthod Craniofac Res 2010; 13:169-178.

25. Takazakura D, Ueki K, Nakagawa K, Marukawa K, Shimada M, Shamiul A, Yamamoto E. A comparison of postoperative hypoesthesia between two types of sagittal split ramus osteotomy and intraoral vertical ramus osteotomy, using the trigeminal somatosensory-evoked potential method. Int J Oral Maxillofac Surg 2007; 36:1114.

26. Teerijoki-Oksa T, Jääskeläinen SK, Soukka T, Virtanen A, Forssell H. Subjective sensory symptoms associated with axonal and demyelinating nerve injuries after mandibular sagittal split osteotomy. J Oral Maxillofac Surg 2011; 69:e208-e213.

27. Tsuji Y, Muto T, Kawakami J, Takeda S. Computed tomographic analysis of the position and course of the mandibular canal: relevance to the sagittal split ramus osteotomy. Int J Oral Maxillofac Surg 2005; 34: 243-246. 